\title{
Crystal structure of the co-crystal $N, N^{\prime}$-bis(3- pyridylmethyl)oxalamide acetic acid (1/2), $\mathrm{C}_{14} \mathrm{H}_{14} \mathrm{~N}_{4} \mathrm{O}_{2} \cdot 2 \mathrm{C}_{2} \mathrm{H}_{4} \mathrm{O}_{2}$
}

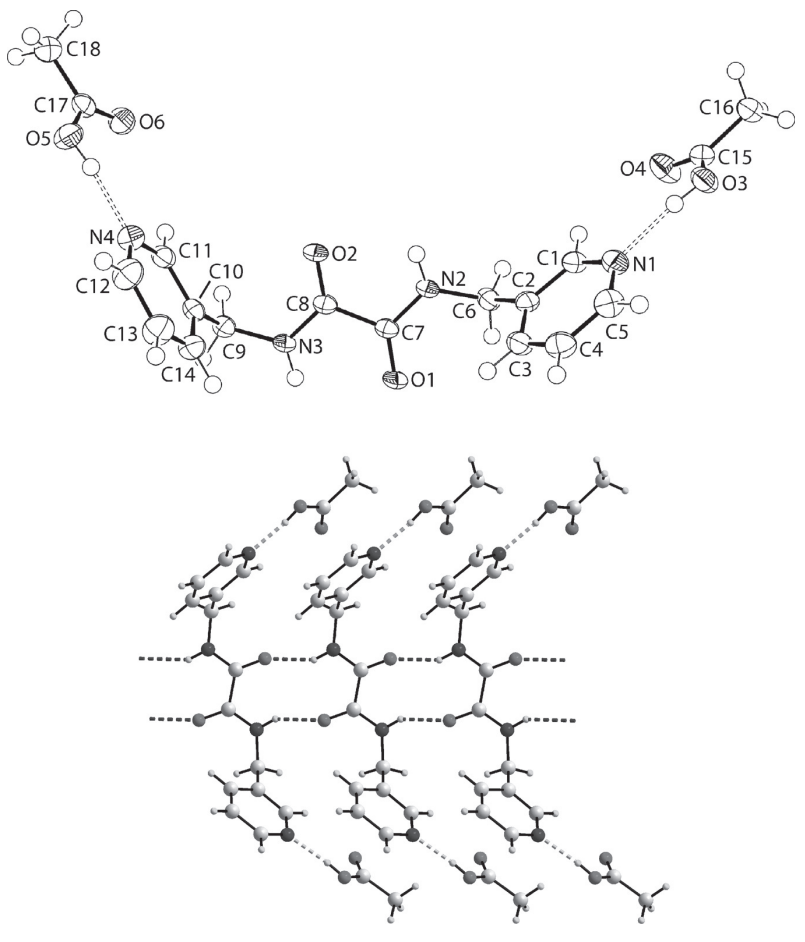

https://doi.org/10.1515/ncrs-2019-0478

Received July 9, 2019; accepted July 26, 2019; available online August 23, 2019

\begin{abstract}
$\mathrm{C}_{18} \mathrm{H}_{22} \mathrm{~N}_{4} \mathrm{O}_{6}$, triclinic, $P \overline{1} \quad$ (no. 2), $\quad a=5.03050(10) \AA$, $b=12.4151(4) \AA, \quad c=15.5353(5) \AA, \quad \alpha=96.186(3)^{\circ}$, $\beta=98.961(2)^{\circ}, \quad \gamma=96.669(2)^{\circ}, \quad V=944.05(5) \AA^{3}, \quad Z=2$, $R_{\mathrm{gt}}(F)=0.0421, w R_{\mathrm{ref}}\left(F^{2}\right)=0.1213, T=100 \mathrm{~K}$.
\end{abstract}

\section{CCDC no.: 1943424}

The molecular structure is shown in the figure. Table 1 contains crystallographic data and Table 2 contains the list of

\footnotetext{
*Corresponding author: Edward R.T. Tiekink, Research Centre for Crystalline Materials, School of Science and Technology, Sunway University, 47500 Bandar Sunway, Selangor Darul Ehsan, Malaysia, e-mail: edwardt@sunway.edu.my,Edward.Tiekink@gmail.com Sang Loon Tan: Research Centre for Crystalline Materials, School of Science and Technology, Sunway University, 47500 Bandar Sunway, Selangor Darul Ehsan, Malaysia
}

Table 1: Data collection and handling.

\begin{tabular}{ll}
\hline Crystal: & Colourless prism \\
Size: & $0.12 \times 0.06 \times 0.03 \mathrm{~mm}$ \\
Wavelength: & Cu $K \alpha$ radiation $(1.54184 \AA$ A $)$ \\
$\mu:$ & $0.88 \mathrm{~mm}^{-1}$ \\
Diffractometer, scan mode: & XtaLAB Synergy, $\omega$ \\
$\theta_{\text {max }}$, completeness: & $76.4^{\circ},>99 \%$ \\
$N\left(h k l_{\text {measured }}, N(h k l)_{\text {unique }}, R_{\text {int }}:\right.$ & $23452,3961,0.046$ \\
Criterion for $I_{\text {obs }}, N(h k l)_{\mathrm{gt}}:$ & $I_{\text {obs }}>2 \sigma\left(I_{\text {obs }}\right), 3434$ \\
$N(\text { param })_{\text {refined }}:$ & 267 \\
Programs: & CrysAlis \\
& WinGX $[1]$, SHELX [2, 3], \\
&
\end{tabular}

the atoms including atomic coordinates and displacement parameters.

\section{Source of material}

$N, N^{\prime}$-Bis(pyridin-3-ylmethyl)oxalamide, ${ }^{3} \mathrm{LH}_{2}$, was prepared according to the literature procedure [5] (melting point, m.pt: 474-475 K). The title co-crystal was prepared by dissolving ${ }^{3} \mathrm{LH}_{2}(0.154 \mathrm{~g}, 1 \mathrm{mmol})$ in an excess of glacial acetic acid $(3 \mathrm{~mL})$. Upon its dissolution, benzene $(3 \mathrm{~mL})$ was carefully layered on top of the solution. Colourless crystals formed approximately one week after the crystallisation and shown crystallographically to be ${ }^{3} \mathrm{LH}_{2} \cdot 2 \mathrm{CH}_{3} \mathrm{C}(=\mathrm{O}) \mathrm{OH}$. M.pt: $373-374 \mathrm{~K}$. IR (ATR, $\left.\mathrm{cm}^{-1}\right)$ : 3323-3282(m) v(N-H), 3152-2934(w) v(C-H), 1697-1660(s) v(C=0), 1516(s) v(C=C), $1361(\mathrm{~m}) v(\mathrm{C}-\mathrm{N}), 802(\mathrm{~s}) \delta(\mathrm{C}=\mathrm{C})$.

\section{Experimental details}

The $\mathrm{C}$-bound $\mathrm{H}$ atoms were geometrically placed $(\mathrm{C}-\mathrm{H}=$ 0.95-0.99 $\AA$ ) and refined as riding with $U_{\text {iso }}(\mathrm{H})=1.2-$ $1.5 U_{\text {eq }}(\mathrm{C})$. The $\mathrm{O}$ - and $\mathrm{N}$-bound $\mathrm{H}$-atoms were located in a difference Fourier map but were refined with distance restraints of $\mathrm{O}-\mathrm{H}=0.84 \pm 0.01 \AA$ and $\mathrm{N}-\mathrm{H}=0.88 \pm 0.01 \AA$, respectively, and with $U_{\text {iso }}(\mathrm{H})$ set to $1.5 U_{\text {equiv }}(\mathrm{O})$ and $1.2 U_{\text {equiv }}(\mathrm{N})$, respectively.

\section{Comment}

A recent review [6] has summarised the structural chemistry of co-crystals, salts and metal complexes 
Table 2: Fractional atomic coordinates and isotropic or equivalent isotropic displacement parameters $\left(\AA^{2}\right)$.

\begin{tabular}{|c|c|c|c|c|}
\hline Atom & $x$ & $y$ & $z$ & $U_{\text {iso }}{ }^{*} / U_{\text {eq }}$ \\
\hline 1 & $0.46011(17)$ & $0.26057(8)$ & $0.44552(7)$ & $0.0227(2)$ \\
\hline 02 & $.08150(17)$ & $0.40313(8)$ & $0.56093(7)$ & $0.0217(2)$ \\
\hline N1 & $1.1023(2)$ & $-0.08529(10)$ & $0.29420(8)$ & $0.0229(3)$ \\
\hline N2 & $0.8899(2)$ & $0.25133(9)$ & $0.41867(8)$ & $0.0181(2)$ \\
\hline $\mathrm{H} 2 \mathrm{~N}$ & $1.060(2)$ & $0.2728(14)$ & $0.4409(12)$ & $0.022^{\star}$ \\
\hline N3 & $0.6514(2)$ & $0.41745(9)$ & $0.58355(8)$ & $0.0182(2)$ \\
\hline $\mathrm{H} 3 \mathrm{~N}$ & $0.480(2)$ & $0.3944(14)$ & $0.5640(12)$ & $0.022^{*}$ \\
\hline N4 & $1.2770(2)$ & $0.52811(10)$ & $.85107(9)$ & $0.0238(3)$ \\
\hline $\mathrm{C} 1$ & $1.0502(3)$ & $0.01818(11)$ & $0.29399(10)$ & $0.0201(3)$ \\
\hline $\mathrm{H} 1$ & 1.137845 & 0.062813 & 0.257911 & $0.024^{*}$ \\
\hline $\mathrm{C} 2$ & $0.8744(2)$ & $0.06351(11)$ & $0.34394(9)$ & $0.0190(3)$ \\
\hline C3 & $0.7520(3)$ & $-0.00171(12)$ & $0.39765(10)$ & $0.0225(3)$ \\
\hline H3 & 0.632169 & 0.026598 & 3174 & $027^{*}$ \\
\hline $\mathrm{C} 4$ & $0.8059(3)$ & $-0.10883(12)$ & $0.39916(10)$ & $0.0254(3)$ \\
\hline H4 & 276 & -0.154651 & 906 & $30 *$ \\
\hline C5 & $0.9802(3)$ & $-0.14727(12)$ & $0.34570(11)$ & $0.0255(3)$ \\
\hline H5 & 1.014323 & 945 & 12 & 31 * \\
\hline C6 & $0.8186(3)$ & 0.1791 & 7(9) & $0.0198(3)$ \\
\hline H6A & 0.923027 & 3994 & 541 & $0.024^{*}$ \\
\hline H6B & 258 & 041 & 681 & $24^{*}$ \\
\hline$C 7$ & $0.7078(2)$ & $0.28844(11)$ & $0.46330(9)$ & $0.0171(3)$ \\
\hline $\mathrm{C} 8$ & $0.8337(2)$ & 0.37 & (9) & $2(3)$ \\
\hline C9 & $0.7312(3)$ & $0.50968(11)$ & $0.65300(10)$ & $0.0202(3)$ \\
\hline $\mathrm{H} 9 \mathrm{~A}$ & 0.565877 & 0.539501 & 0.666288 & $.024^{\star}$ \\
\hline H9B & 0.844765 & 0.567872 & 0.631190 & $0.024^{*}$ \\
\hline C10 & $0.8865(3)$ & 11) & 2(9) & $2(3)$ \\
\hline 11 & $6(3)$ & 0.543 & 0.7747 & $0.0200(3)$ \\
\hline $\mathrm{H} 11$ & 01970 & 0.600576 & 0.744778 & $0.024^{*}$ \\
\hline C12 & $1.1788(3)$ & $0.44756(13)$ & $0.89287(11)$ & $0.0290(3)$ \\
\hline $\mathrm{H} 12$ & 1.279306 & 0.436054 & 0.947378 & $0.035^{\star}$ \\
\hline C13 & $373(3)$ & 0.3803 & 0.860 & $.0299(3)$ \\
\hline $\mathrm{H} 13$ & 975 & 96 & 84 & $0.036^{\star}$ \\
\hline C14 & $0.7890(3)$ & $0.39754(11)$ & $0.78080(10)$ & $0.0242(3)$ \\
\hline $\mathrm{H} 14$ & 22540 & 0.352433 & 6879 & $0.029 *$ \\
\hline 03 & 448(2) & $-0.14942(8)$ & $0.18767(8)$ & $.0256(2)$ \\
\hline $\mathrm{H} 30$ & $5(4)$ & $52(17)$ & (12) & $0.038^{*}$ \\
\hline 04 & 4(2) & 7(9) & $9(8)$ & $0.0319(3)$ \\
\hline C15 & $974(3)$ & $-0.07653(11)$ & $0.13447(10)$ & $0.0217(3)$ \\
\hline C16 & $1.6897(3)$ & $-0.10963(13)$ & $0.07447(10)$ & $0.0259(3)$ \\
\hline $\mathrm{H} 16 \mathrm{~A}$ & 1.649220 & -0.078589 & 0.019269 & $0.039 *$ \\
\hline H16B & 1.668207 & -0.189548 & 0.062228 & $0.039 *$ \\
\hline $\mathrm{H} 16 \mathrm{C}$ & 1.876909 & -0.082296 & 0.102827 & $0.039 *$ \\
\hline 05 & $1.7283(2)$ & $0.66193(9)$ & $0.92028(7)$ & $0.0262(2)$ \\
\hline $\mathrm{H} 50$ & $1.589(3)$ & $0.6206(15)$ & $0.8934(13)$ & $0.039^{\star}$ \\
\hline 06 & $1.7052(2)$ & $0.72550(8)$ & $0.79044(7)$ & $0.0252(2)$ \\
\hline C17 & $1.8173(3)$ & $0.72694(11)$ & $0.86564(10)$ & $0.0205(3)$ \\
\hline C18 & $2.0714(3)$ & $0.80222(13)$ & $0.90705(11)$ & $0.0279(3)$ \\
\hline $\mathrm{H} 18 \mathrm{~A}$ & 2.191622 & 0.810727 & 0.863596 & $0.042^{*}$ \\
\hline $\mathrm{H} 18 \mathrm{~B}$ & & 0.771237 & 0.956931 & $0.042^{\star}$ \\
\hline $\mathrm{H} 18 \mathrm{C}$ & 2.023887 & 0.873772 & 0.927622 & $0.042^{*}$ \\
\hline
\end{tabular}

formed by isomeric molecules with the general formula $\left(n-\mathrm{C}_{5} \mathrm{H}_{4} \mathrm{~N}\right) \mathrm{CH}_{2} \mathrm{~N}(\mathrm{H}) \mathrm{C}(=\mathrm{O}) \mathrm{C}(=\mathrm{O}) \mathrm{N}(\mathrm{H}) \mathrm{CH}_{2}\left(\mathrm{C}_{5} \mathrm{H}_{4} \mathrm{~N}-\mathrm{n}\right)$, for $\mathrm{n}=2$, 3 and 4, hereafter abbreviated as ${ }^{n} \mathrm{LH}_{2}$. Hydrogen bonding functionality is apparent in these molecules, namely in the central di-amide group as well as in the two terminal pyridyl residues. As a part of on-going studies in forming co-crystals and coordination polymers of ${ }^{n} \mathrm{LH}_{2}$ [7-9], the title 2:1 cocrystal, ${ }^{3} \mathrm{LH}_{2} \cdot 2 \mathrm{CH}_{3} \mathrm{C}(=0) \mathrm{OH}$, was formed and characterised crystallographically.

The molecular structures of the molecules comprising the asymmetric unit are shown in the figure $(70 \%$ displacement ellipsoids). The ${ }^{3} \mathrm{LH}_{2}$ molecule features a planar, central $\mathrm{C}_{2} \mathrm{~N}_{2} \mathrm{O}_{2}$ residue with the r.m.s. deviation of the fitted atoms $=0.0204 \AA$; the maximum deviation from the plane is $0.0286(7) \AA$ for the N2 atom. The planarity does not extend to the appended methylene-carbon atoms which lie 0.207(2) $\AA$, for the C6 atom, and 0.189(2) $\AA$, for C9, to one side of the plane through the central atoms. Indeed, the pyridyl rings lie to the same side of the molecule so that the conformation is syn-periplanar. The dihedral angles between the central plane and the N1- and N4-pyridyl rings are $71.34(4)$ and $77.78(4)^{\circ}$, respectively; the dihedral angle between the pyridyl rings is $85.83(4)^{\circ}$. The observed synperiplanar conformation is found in one of the two polymorphs of ${ }^{3} \mathrm{LH}_{2}$, the other exhibiting an anti-periplanar conformation in each of the independent molecules [10]. DFT calculations showed the energy difference between the two observed conformations in the polymorphs was less than $1 \mathrm{kcal} \mathrm{mol}^{-1}$, consistent with the conformational flexibility of these molecules [6]. Finally, two intramolecular amide$\mathrm{N}-\mathrm{H} \cdots \mathrm{O}$ (amide) hydrogen bonds are noted $[\mathrm{N} 2-\mathrm{H} 2 \mathrm{n} \cdots \mathrm{O} 2$ : $\mathrm{H} 2 \mathrm{n} \cdots \mathrm{O} 2=2.314(18) \AA$, N2 $\cdots \mathrm{O} 2=2.7170(16) \AA$ with angle at $\mathrm{H} 2 \mathrm{n}=108.4(11)^{\circ}$ and N3-H3n $\cdots \mathrm{O} 1: \mathrm{H} 3 \mathrm{n} \cdots \mathrm{O} 1=2.325(18) \AA$, $\mathrm{N} 3 \cdots 01=2.7091(16) \AA \AA$ with angle at $\left.\mathrm{H} 3 \mathrm{n}=106.9(12)^{\circ}\right]$; each of these gives rise to an $S(5)$ loop using graph-set notation [11]. The acetic acid molecules are attached to ${ }^{3} \mathrm{LH}_{2}$ via hydroxy- $\mathrm{O}-\mathrm{H} \cdots \mathrm{N}$ (pyridyl) hydrogen bonds, indicated by dashed bonds in the figure. The great disparity in the $\mathrm{C}-$ 0 bonds confirms the location of the acidic protons in the carboxylic acids [C15-03, $04=1.3213(18)$ and 1.2163(18) $\AA$; C17-05, O6 = 1.3244(18) and 1.2129(18) Å].

As mentioned above, conventional hydroxy-O$\mathrm{H} \cdots \mathrm{N}$ (pyridyl) hydrogen bonds link the components of the asymmetric unit into a three-molecular aggregate [03H3o $\cdots \mathrm{N} 1: \quad \mathrm{H} 30 \cdots \mathrm{N} 1=1.85(2) \AA, \quad \mathrm{O} \cdots \mathrm{N} 1=2.6952(16) \AA$ with angle at $\mathrm{H} 3 \mathrm{O}=174(2)^{\circ}$ and $\mathrm{O} 5-\mathrm{H} 50 \cdots \mathrm{N} 4$ : H5o $\cdots \mathrm{N} 4=1.820(17) \AA$, O5 $\cdots \mathrm{N} 4=2.6550(16) \AA$ with angle at $\left.\mathrm{H} 50=172(2)^{\circ}\right]$. The di-amide residues self-associate to form a supramolecular tape along the a-axis direction and mediated by 10 -membered $\left\{\cdots \mathrm{HNC}_{2} \mathrm{O}\right\}_{2}$ synthons, as shown in the lower view of the figure [N2$\mathrm{H} 2 \mathrm{n} \cdots \mathrm{O} 1^{\mathrm{i}}: \mathrm{H} 2 \mathrm{n} \cdots \mathrm{O} 1^{\mathrm{i}}=2.027(11) \AA \AA \mathrm{N} 2 \cdots \mathrm{O} 1^{\mathrm{i}}=2.8206(14) \AA$ with angle at $\mathrm{H} 2 \mathrm{n}=151.2(16)^{\circ}$ and $\mathrm{N} 3-\mathrm{H} 3 \mathrm{n} \cdots \mathrm{O}{ }^{\mathrm{ii}}$ : $\mathrm{H} 3 \mathrm{n} \cdots \mathrm{O} 2^{\mathrm{ii}}=2.014(11) \AA ̊ . \mathrm{N} 3 \cdots \mathrm{O} 2^{\mathrm{ii}}=2.8157(14) \AA ̊$ with angle 
at $\mathrm{H} 3 \mathrm{n}=152.5(16)^{\circ}$ for symmetry operations (i) $1+\mathrm{x}, \mathrm{y}, \mathrm{z}$ and (ii) $-1+x, y, z]$. The tapes are connected into a layer in the ac-plane by methylene- $\mathrm{C}-\mathrm{H} \cdots \mathrm{O}$ (carbonyl) [C6H6a $\cdots$ O $^{\mathrm{iii}}$ : H6a $\cdots \mathrm{O}^{\mathrm{iii}}=2.54 \AA$, C6 $\cdots \mathrm{O}^{\mathrm{iii}}=3.5045(18) \AA$ with angle at $\mathrm{H} 6 \mathrm{a}=165^{\circ}$ for (iii) $3-\mathrm{x}, 1-\mathrm{y}, 1-\mathrm{z}$ ] and pyridyl$\mathrm{C}-\mathrm{H} \cdots \mathrm{O}$ (hydroxy) [C12-H12 $\cdots \mathrm{O}^{\mathrm{iv}}: \mathrm{H} 12 \cdots \mathrm{O} 5^{\mathrm{iv}}=2.50 \AA$, $\mathrm{C} 12 \cdots \mathrm{O} 5^{\mathrm{iv}}=3.327(2) \AA$ with angle at $\mathrm{H} 12=145^{\circ}$ for (iv) $3-\mathrm{x}, 1-\mathrm{y}, 2-\mathrm{z}$. The connections between layers along the $b$-axis direction are also of the type $\mathrm{C}-\mathrm{H} \cdots \mathrm{O}$ but at longer separations that is, pyridyl- $\mathrm{C}-\mathrm{H} \cdots \mathrm{O}$ (amide) [C4$\mathrm{H} 4 \cdots \mathrm{O} 1^{\mathrm{v}}: \mathrm{H} 4 \cdots \mathrm{O} 1^{\mathrm{v}}=2.60 \AA, \mathrm{C} 4 \cdots \mathrm{O} 1^{\mathrm{v}}=3.544(2) \AA$ with angle at $\mathrm{H} 4=172^{\circ}$ for (v) $1-\mathrm{x},-\mathrm{y}, 1-\mathrm{z}$ ] and methyl-C$\mathrm{H} \cdots \mathrm{O}$ (amide) $\left[\mathrm{C} 16-\mathrm{H} 16 \mathrm{a} \cdots \mathrm{O} 1^{\mathrm{vi}}: \mathrm{H} 16 \mathrm{a} \cdots \mathrm{O} 1^{\mathrm{vi}}=2.61 \AA\right.$, $\mathrm{C} 16 \cdots \mathrm{O}^{\mathrm{vi}}=3.585(2) \AA$ with angle at $\mathrm{H} 16 \mathrm{a}=172^{\circ}$ for (vi) $3-\mathrm{x},-\mathrm{y},-\mathrm{z}]$ interactions.

In order to understand more about the supramolecular interactions important in the molecular packing, Crystal Explorer 17 [12] was used for the calculation of the Hirshfeld surfaces as well as of the full and delineated two-dimensional fingerprint plots for the entire three-molecule aggregate using established procedures [13]. Important contributions to the calculated Hirshfeld surface come from $\mathrm{H} \cdots \mathrm{H}$ [44.1\%] and $\mathrm{O} \cdots \mathrm{H} / \mathrm{H} \cdots \mathrm{O}[30.0 \%]$ contacts, the latter reflecting the significant $\mathrm{H} \cdots \mathrm{O}$ contacts identified above. Other important surface contacts come from $\mathrm{C} \cdots \mathrm{H} / \mathrm{H} \cdots \mathrm{C}[14.4 \%]$ as well as $\mathrm{N} \cdots \mathrm{H} / \mathrm{H} \cdots \mathrm{N}[4.7 \%]$ and $\mathrm{O} \cdots \mathrm{C} / \mathrm{C} \cdots \mathrm{O}[3.2 \%]$ contacts but, generally at distances greater than the sum of the respective van der Waals radii. The same calculations were also performed on each of the crystallographically independent components of the asymmetric unit. As anticipated, several differences in percentage contributions to the surface are apparent. For ${ }^{3} \mathrm{LH}_{2}$, the contributions from $\mathrm{H} \cdots \mathrm{H}[40.6 \%]$ and $\mathrm{O} \cdots \mathrm{H} / \mathrm{H} \cdots \mathrm{O}[25.3 \%]$ contacts have decreased significantly while those from $\mathrm{N} \cdots \mathrm{H} / \mathrm{H} \cdots \mathrm{N}[11.0 \%]$ and $\mathrm{C} \cdots \mathrm{H} / \mathrm{H} \cdots \mathrm{C}$ [16.9\%] have increased compared with the overall threemolecule aggregate. A recent study [14] highlighted how the analysis of calculated Hirshfeld surfaces could be employed to distinguish between different molecules in the asymmetric unit. This is also true in the present case of the 03and 05-carboxylic acids. Hence, differences in the percentage contributions to the overall surfaces for each molecule are apparent in the $\mathrm{H} \cdots \mathrm{H}[41.4 \%$ compared with $43.7 \%$ for the O3- and 05-carboxylic acids, respectively], $\mathrm{O} \cdots \mathrm{H} / \mathrm{H} \cdots \mathrm{O}$ [38.1 and 37.8\%] and $\mathrm{C} \cdots \mathrm{H} / \mathrm{H} \cdots \mathrm{C}$ [6.1 and 4.4\%]; the contributions from $\mathrm{N} \cdots \mathrm{H} / \mathrm{H} \cdots \mathrm{N}$ contacts remain the same [8.1 and $8.2 \%]$.

Similar overall percentage contributions calculated for the three-molecule aggregate in the title co-crystal were noted in a very closely related structure, that is, ${ }^{4} \mathrm{LH}_{2} \cdot 2 \mathrm{CH}_{3} \mathrm{C}(=\mathrm{O}) \mathrm{OH}$, isolated as a dihydrate [15]; the calculations were performed on the overall five-molecule aggregate.
Here, despite the presence of water molecules of crystallisation that participate in significant hydrogen bonding interactions, the most important contribution to the Hirshfeld surface still comes from $\mathrm{H} \cdot \mathrm{H}$ contacts [43.4\%] with $\mathrm{O} \cdots \mathrm{H} / \mathrm{H} \cdots \mathrm{O}[32.5 \%$ ] contacts being a little more important than in the title structure. Contacts of the type $\mathrm{H} \cdots \mathrm{C} / \mathrm{C} \cdot \mathrm{H}$ [14.4\%] also make a significant contribution to the surface but, again at relatively long separations.

Acknowledgements: Sunway University Sdn Bhd is thanked for financial support of this work through Grant no. STRRCTR-RCCM-001-2019.

\section{References}

1. Rigaku OD. CrysAlis ${ }^{\mathrm{PRO}}$. Rigaku Oxford Diffraction Ltd, Yarnton, England (2017).

2. Sheldrick, G. M.: A short history of SHELX. Acta Crystallogr. A64 (2008) 112-122.

3. Sheldrick, G. M.: Crystal structure refinement with SHELXL. Acta Crystallogr. C71 (2015) 3-8.

4. Farrugia, L. J.: WinGX and ORTEP for Windows: an update. J. Appl. Crystallogr. 45 (2012) 849-854.

5. Schauer, C. L.; Matwey, E.; Fowler, F. W.; Lauher, J. W.: Controlled spacing of metal atoms via ligand hydrogen bonds. J. Am. Chem. Soc. 119 (1997) 10245-10246.

6. Tiekink, E. R. T.: Multi-component crystals: synthesis, concepts, function. (Ed. Tiekink E. R. T. and Schpector-Zukerman J.) p. 289-319, De Gruyter: Singapore (2017).

7. Tan, S. L.; Tiekink, E. R. T.: N,N'-bis(4-Pyridylmethyl)oxalamide benzene solvate: crystal structure, Hirshfeld surface analysis and computational study. Acta Crystallogr. E75 (2019) 1133-1139.

8. Tan, S. L.; Tiekink, E. R. T.: Crystal structure of the co-crystal $N, N^{\prime}$-bis(4-pyridylmethyl)oxalamide and 2,3,5,6-tetrafluoro1,4-di-iodobenzene (1/1), $\mathrm{C}_{14} \mathrm{H}_{14} \mathrm{~N}_{4} \mathrm{O}_{2} \cdot \mathrm{C}_{6} \mathrm{~F}_{4} \mathrm{I}_{2}$. Z. Kristallogr. NCS 234 (2019) 1117-1119.

9. Tan, Y. S.; Chun, H. Z.; Jotani, M. M.; Tiekink, E. R. T.: Steric control of supramolecular association in structures of $\mathrm{Zn}\left(\mathrm{S}_{2} \mathrm{COR}\right)_{2}$ with $N, N^{\prime}$-bis(pyridin-4-ylmethyl)oxalamide. Z. Kristallogr. 234 (2019) $165-175$.

10. Jotani, M. M.; Zukerman-Schpector, J.; Sousa Madureira, L.; Poplaukhin, P.; Arman, H. D.; Miller, T.; Tiekink, E. R. T.: Structural, Hirshfeld surface and theoretical analysis of two conformational polymorphs of $N, N^{\prime}$-bis(pyridin-3-ylmethyl)oxalamide. Z. Kristallogr. 231 (2016) 415-425.

11. Bernstein, J.; Davis, R. E.; Shimoni, L.; Chang, N.-L.: Patterns in hydrogen bonding: functionality and graph set analysis in crystals. Angew. Chem. Int. Ed. 34 (1995) 1555-1573.

12. Turner, M. J.; Mckinnon, J. J.; Wolff, S. K.; Grimwood, D. J.; Spackman, P. R.; Jayatilaka, D.; Spackman, M. A.: Crystal Explorer v17. The University of Western Australia, Australia (2017).

13. Tan, S. L.; Jotani, M. M.; Tiekink, E. R. T.: Utilizing Hirshfeld surface calculations, non-covalent interaction $(\mathrm{NCl})$ plots and the calculation of interaction energies in the analysis of molecular packing. Acta Crystallogr. E75 (2019) 308-318. 
14. Tan, S. L.; Tiekink, E. R. T.: Crystal structure of the 1:2 co-crystal between $N, N^{\prime}$-bis(4-pyridylmethyl)oxalamide and acetic acid as a dihydrate, $\mathrm{C}_{14} \mathrm{H}_{14} \mathrm{~N}_{4} \mathrm{O}_{2} \cdot 2 \mathrm{C}_{2} \mathrm{H}_{4} \mathrm{O}_{2} \cdot 2 \mathrm{H}_{2} \mathrm{O}$. Z. Kristallogr. NCS 234 (2019) 1109-1111.
15. Jotani, M. M.; Wardell, J. L.; Tiekink, E. R. T.: Supramolecular association in the triclinic $\left(Z^{\prime}=1\right)$ and monoclinic $\left(Z^{\prime}=4\right)$ polymorphs of 4-(4-acetylphenyl)piperazin-1-ium 2-amino-4nitrobenzoate. Z. Kristallogr. Cryst. Mat. 234 (2019) 43-57. 